\title{
EFFECT OF PEDAL TRAINING ON GAIT SPEED IN CHILDREN WITH HEMIPARETIC CEREBRAL PALSY
}

\author{
Nahla M. Ibrahim, Mai Elsayed Abbass *.
}

Faculty of physical therapy, Cairo University, Giza, Egypt.

\section{ABSTRACT}

Background: Cerebral palsy is associated with impairment in functional performance, balance and gait

Objective: Slow walking speed represents the major functional problems in children with cerebral palsy; our aim was to improve the average speed of gait by increasing the number of repetitive cycles by pedaling.

Design: Biodex gait trainer was used to assess average walking speed and step length in twenty hemiparetic cerebral palsy children, who were divided into study and control groups. Both groups had received the prescribed rehabilitation program. Study group had received $20-\mathrm{min}$ pedal exercise in addition to the exercise program.

Results: In post treatment results, there was significant improvement in speed for both groups in favor to study group and a significant improvement in step length in the study group, with non-significant improvement in step length in the control group.

Conclusion: Adding pedal exercise to the rehabilitation program for children with hemiparetic cerebral palsy causes improvement in walking average speed.

KEY WORDS: Pedaling, Gait, Speed, Hemiparesis, Cerebral palsy.

Address for correspondence: Dr. Mai Elsayed Abbass, Faculty of physical therapy, Cairo University, Giza, Egypt. E-Mail: mai.tamer.elmasry@gmail.com

\section{Access this Article online}

Quick Response code

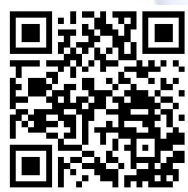

DOI: $10.16965 /$ ijpr.2017.249
International Journal of Physiotherapy and Research ISSN 2321- 1822

www.ijmhr.org/ijpr.html

Received: 16-10-2017

Peer Review: 17-10-2017

Revised: None
Accepted: 15-11-2017

Published (0): 11-12-2017

Published (P): 11-12-2017

\section{INTRODUCTION}

Cerebral palsy $(\mathrm{CP})$ is a brain injury that results in disorder in movement and posture associated with impairment in functional performance, balance and gait [1].one of its most common type is hemiplegia, children with hemiplegic cerebral palsy has involvement of one side of the body usually associated with injury of one hemisphere that occasionally occurs in the utero or during delivery or in the first 2 years of live [2].

Gait is one of the most important motor functions which require high sensorimotor integration. In hemiparetic children muscle weakness results in impaired motor control that causes walking impairment [3]. Nearly, three quarter of cerebral palsy children are ambulant. The pattern of their gait is the issue of interest as most of them had abnormal gait kinematics. Hemiparetic gait is asymmetric as the non-affected limb produces more work than the affected [4]. Most of ambulant children with $C P$ have asymmetric gait and slow velocity when compared with their peers [5].

Speed is considered the most global indicator of functional mobility as it is the only measurement to be affected in any gait abnormalities. Other gait measurements are speed dependent and the more sever is the impairment, the less speed of gait [6].Walking speed is the distance 
covered in a given time. The instantaneous speed varies from one instant to another during the walking cycle, but the average speed is the product of the cadence and the stride length [7].

Instrumented gait analysis is an objective method that helps the clinician to quantitatively interpret the patient pattern of gait [8]. Biodex gait trainer $2 \mathrm{TM}$ is a valid and reliable tool used to asses and train gait for all patients using visual feedback and it helps monitor and record different gait kinematic parameters [9].Both pattern of walking and cycling are similar as they require reciprocal flexion and extension of lower limbs in combination with adequate and coordinated manner [10].

Lower limb cycling is an effective rehabilitation tool that can be added to the physical therapy program to promote high speed of movement by improving muscle control more than other daily activities performed by most of CP children [11].

This study aimed at evaluating the effect of pedal training on improving the speed of gait in children with hemiparesis.

\section{METHODS}

Participants: Inclusion criteria: Twenty children with hemiparetic CP (Their age ranged from 8 to 11 years of both gender, their height was more than 1 meter were selected from the pediatric outpatient clinic of our institution. They were divided into 2 groups (study and control). Selected subjects had gait performance level II in GMFCS (Gross Motor Functional Classification System), they were able to follow simple instructions. All assessed children had slow average walking speed and short step length during gait as recorded from the Biodex gait trainer assessment.

Exclusion Criteria 1- Sever lower limb orthopedic deformities and contractures which may interfere with the patient performance of pedaling exercises 2-recent lower limb surgery in the last 6 month before starting the study.3patients who were wearing lower limb orthoses (hip, knee or ankle foot orthoses).

Patients were divided into two groups as follow:

Study group (A): 10 children with hemiparetic cerebral palsy had received 20 minutes pedal training in addition to the selected prescribed exercises (One hour). Control group (B): 10 children with hemiparetic cerebral palsy children had received the selected prescribed exercise program (One hour).

\section{MATERIALS}

GMFCS: for selection of patients. level II (walk without assistance but with limitations [12].

Valid and reliable weight and height scale (to measure the height and weight for all children participated in the study as a prerequisite before assessment on the Biodex gait trainer).

Biodex gait trainer 2 TM: for evaluation, pre-and post- 6 weeks of training program.

4- Portable and adjustable bicycle for lower limb (pedal): a small and light pedal cycle with a feet platform and straps that help to support the child feet in place without slippage during exercise. It was placed on the ground in front of a small back supported chair that allow the child to sit comfortably and perform the pedal cycling.

\section{Methods For evaluation}

The Biodex Gait Trainer: The Biodex Gait Trainer 2TM was used to evaluate the average speed and step length of the subjects. At first, subjects' data (name, age, gender, weight and height) were fed to the device. Then the child was asked to stand on the device holding on its side rails (holding only at the begin to ensure safety and before recording), and look forward at the screen then duration of assessment was selected to be 10 minutes, the children were left to be familiar with the device before we started the assessment. After they had been familiar the assessment began first with slow speed and no inclination then it was increased gradually up to a comfortable speed so that speed could be recorded .Test was repeated 3 times and the average speed and step length were then recorded.

\section{For treatment:}

Physical therapy tools: mat, wedge, balance board and parallel bar to conduct the selected physical therapy exercise program for children of both groups.

Stationary cycle pedal: Patients of the study 
group were given a pedal program for $20 \mathrm{~min}$ utes in addition to their selected prescribed exercise program ( 1 hour), 3days per week for 6 successive weeks.

Children were asked to sit on a back-support chair keeping their back angle 100 degree. While the children were wearing their shoes, the straps were fit to their feet well before starting the exercise. Then they began to move the pedal forward for 10 minutes then backward for 10 minutes. Patients were asked to pedal at their comfortable speed, keeping their back supported.

Pedal was divided into forward and backward cycles. Forward cycle (clockwise direction) consists of 2 phases:

Phase I (extension phase) the pedal is near the body and the leg will move into extension while the other leg is flexed.

Phase II (flexion phase) the pedal is away from the body and the knee moved toward flexion while the other is extended.

Backward cycle (counter clockwise direction): phase 1 (extension phase): started with their feet away keeping their leg extended and then move back toward flexion in counterclockwise direction. Phase II (flexion phase): from flexed leg into extended limb.

Children were encouraged to complete their pedaling in a complete circle and to increase their speed of pedaling by time.

Children of both groups had received the selected prescribed exercise program, including the following:

Progressive resisted exercises using sand bags for weak muscles at the affected side for hip extensors and abductors, knee extensors and ankle dorsiflexors, and for upper limb shoulder, elbow and wrist extensor muscles.

Flexibility exercises to the tight lower limb muscles aiming at maintaining the normal length of the muscles (hip flexors, hamstring and calf muscles) at the affected side (shoulder, elbow flexors and forearm pronators) for upper limb.

Balance exercises: Static balance from standing position on balance board with graduation. Walking on balance board.
Gait training: Walking between parallel bars using obstacles (rolls, wedges with different height). Walking with therapist assistance on stepper. Walking on different surfaces (mat, floor and carpets) to improve the proprioceptive sense.

Walking forward, backward and sideways on floor.

Both groups had received the previous exercise program for 1 hour. 3 days per week for successive 6 weeks.

After 6 weeks reevaluation was done by the Biodex gait trainer 2TM, to compare pre-and post-treatment results (speed and step length) for both groups.

Statistical analysis: The results were collected before and after 6 weeks of treatment and analyzed using SPSS software version 17. Paired $t$ test was applied to compare the mean difference within each group while independent sample t-test was applied to compare the mean difference between groups. The alpha level was calculated at .05 .

\section{RESULTS}

Twenty children with hemiparetic cerebral palsy were randomly divided into study group (10 children from both sexes 6 girls and 4 boys) 5 left sided and 5 right sided hemiparesis with mean age 9.7 with $\mathrm{SD}=1.2$ and mean height $137.2 \mathrm{~cm}$ with $\mathrm{SD}=6.5$ and mean weight $32.3 \mathrm{Kg}$ with $\mathrm{SD}=5.8$ and control group (10 children from both sexes 5 girls and 5 boys) 7 left sided and 3 right sided hemiparesis with mean age 9.9 with $\mathrm{SD}=1.2$ and mean height $137.1 \mathrm{~cm}$ with $\mathrm{SD}=6.2$ and mean weight $32 \mathrm{Kg}$ with $\mathrm{SD}=6.01$. The results revealed that significant differences were not found between groups in age ( $P$ value $=0.7$ ), weight $(P$ value $=0.91)$ and height $(P$ value $=0.97)$. Assessment was done by the Biodex gait trainer 2TM to evaluate the gait pattern for children of both groups (speed and step length).

Table 1 shows a comparison of the pretreatment results for speed parameter and Step length parameter of the affected and non-affected limbs for the control and study groups and reveals that there is no significant difference between groups in pretreatment results of speed and step length before treatment. 
Table 1: Comparison of the pretreatment results for the study and control groups.

\section{Abbreviations:}

SD, Standard deviation; MD, Mean difference;

$*$ Level of significance $p<0.05$
Table 2: Comparison of the pre and post-treatment results for the study and control groups.

\section{Abbreviations:}

SD, Standard deviation; $M D$, Mean difference;

* Level of significance $p<0.05$

\begin{tabular}{|c|c|c|c|c|c|}
\hline Variable & Mean & SD & MD & P* value & Significance \\
\hline $\begin{array}{l}\text { Speed parameter for the study } \\
\text { group }\end{array}$ & 0.462 & 0.057 & \multirow{2}{*}{0.037} & \multirow{2}{*}{0.085} & \multirow{2}{*}{ Not-significant } \\
\hline $\begin{array}{l}\text { Speed parameter for the control } \\
\text { group }\end{array}$ & 0.425 & 0.028 & & & \\
\hline $\begin{array}{l}\text { Step length parameter of the } \\
\text { study group For affected limb }\end{array}$ & 0.601 & 0.083 & \multirow{2}{*}{0.027} & \multirow{2}{*}{0.38} & \multirow{2}{*}{ Not-significant } \\
\hline $\begin{array}{l}\text { Step length parameter of the } \\
\text { control group For affected limb }\end{array}$ & 0.574 & 0.045 & & & \\
\hline $\begin{array}{l}\text { Step length parameter of the } \\
\text { study group For non-affected } \\
\operatorname{limb}\end{array}$ & 0.57 & 0.086 & \multirow{2}{*}{0.064} & \multirow{2}{*}{0.18} & \multirow{2}{*}{ Not-significant } \\
\hline $\begin{array}{l}\text { Step length parameter of the } \\
\text { control group For non-affected } \\
\text { limb }\end{array}$ & 0.634 & 0.12 & & & \\
\hline
\end{tabular}

\begin{tabular}{|c|c|c|c|c|c|}
\hline Variable & Mean & SD & MD & $\mathrm{P} *$ value & Significance \\
\hline $\begin{array}{l}\text { Pretreatment results of speed } \\
\text { parameter for the study group }\end{array}$ & 0.462 & 0.057 & \multirow{2}{*}{0.164} & \multirow{2}{*}{0.002} & \multirow{2}{*}{ significant } \\
\hline $\begin{array}{l}\text { Post-treatment results of speed } \\
\text { parameter for the study group }\end{array}$ & 0.626 & 0.114 & & & \\
\hline $\begin{array}{l}\text { Pretreatment results of speed } \\
\text { parameter for the control group }\end{array}$ & 0.425 & 0.028 & \multirow{2}{*}{0.005} & \multirow{2}{*}{0.015} & \multirow{2}{*}{ significant } \\
\hline $\begin{array}{l}\text { Post-treatment results of speed } \\
\text { parameter for the control group }\end{array}$ & 0.43 & 0.029 & & & \\
\hline $\begin{array}{l}\text { Pretreatment results of step length } \\
\text { parameter of the study group For } \\
\text { affected limb }\end{array}$ & 0.601 & 0.083 & \multirow{2}{*}{0.078} & \multirow{2}{*}{0.002} & \multirow{2}{*}{ significant } \\
\hline $\begin{array}{l}\text { Post-treatment results of step length } \\
\text { parameter of the study group For } \\
\text { affected limb }\end{array}$ & 0.679 & 0.119 & & & \\
\hline $\begin{array}{l}\text { Pretreatment results of step length } \\
\text { parameter of the control group For } \\
\text { affected limb }\end{array}$ & 0.574 & 0.045 & \multirow{2}{*}{0.012} & \multirow{2}{*}{0.104} & \multirow{2}{*}{ Not-significant } \\
\hline $\begin{array}{l}\text { Post-treatment results of step length } \\
\text { parameter of the control group For } \\
\text { affected limb }\end{array}$ & 0.586 & 0.049 & & & \\
\hline $\begin{array}{l}\text { Pretreatment results of step length } \\
\text { parameter of the study group For non- } \\
\text { affected limb }\end{array}$ & 0.57 & 0.086 & \multirow{2}{*}{0.075} & \multirow{2}{*}{0.046} & \multirow{2}{*}{ significant } \\
\hline $\begin{array}{l}\text { Post-treatment results of step length } \\
\text { parameter of the study group For non- } \\
\text { affected limb }\end{array}$ & 0.645 & 0.11 & & & \\
\hline $\begin{array}{l}\text { Pretreatment results of step length } \\
\text { parameter of the control group For non- } \\
\text { affected limb }\end{array}$ & 0.634 & 0.12 & \multirow{2}{*}{0.008} & \multirow{2}{*}{0.423} & \multirow{2}{*}{ Not-significant } \\
\hline $\begin{array}{l}\text { Post-treatment results of step length } \\
\text { parameter of the control group For non- } \\
\text { affected limb }\end{array}$ & 0.642 & 0.11 & & & \\
\hline
\end{tabular}

Table 2 shows pre-and post-treatment results for speed and step length parameters for the study and control groups. The results of speed parameter reveal significant improvement in both groups. The significant improvement in speed results in the study group at $p$ value .002 is with a percent of improvement equals 35.49 $\%$.while in the control group at $p$ value .015 with a percent of improvement equals $1.17 \%$. The esults of step length parameter pre-and posttreatment of the affected and non-affected limb of the control group reveal no significant improvement at $p$ value .104 in the affected limb and at $p$ value .423 in the non-affected limbs. The percent of improvement is $1.26 \%$ for the non-affected limbs and $2.09 \%$ for the affected limb. 
Table 3: Comparison of the posttreatment results for the study and control groups.

\section{Abbreviations:}

SD, Standard deviation; MD, Mean difference;

* Level of significance $p<0.05$

\begin{tabular}{|c|c|c|c|c|c|}
\hline Variable & Mean & SD & MD & $\mathrm{P}^{*}$ value & Significance \\
\hline $\begin{array}{l}\text { Speed parameter for the study } \\
\text { group }\end{array}$ & 0.626 & 0.114 & \multirow{2}{*}{0.196} & \multirow{2}{*}{0} & \multirow{2}{*}{ significant } \\
\hline $\begin{array}{l}\text { Speed parameter for the control } \\
\text { group }\end{array}$ & 0.43 & 0.029 & & & \\
\hline $\begin{array}{l}\text { Step length parameter of the } \\
\text { study group For affected limb }\end{array}$ & 0.679 & 0.119 & \multirow{2}{*}{0.036} & \multirow{2}{*}{0.093} & \multirow{2}{*}{$\begin{array}{l}\text { Not- } \\
\text { significant }\end{array}$} \\
\hline $\begin{array}{l}\text { Step length parameter of the } \\
\text { control group For affected limb }\end{array}$ & 0.586 & 0.049 & & & \\
\hline $\begin{array}{l}\text { Step length parameter of the } \\
\text { study group For non-affected limb }\end{array}$ & 0.645 & 0.11 & \multirow{2}{*}{0.952} & \multirow{2}{*}{0.003} & \multirow{2}{*}{ significant } \\
\hline $\begin{array}{l}\text { Step length parameter of the } \\
\text { control group For non-affected } \\
\text { limb }\end{array}$ & 0.642 & 0.11 & & & \\
\hline
\end{tabular}

Table 3 shows post-treatment results for speed and step length parameters for the study and control groups. The results of speed and step length of the non-affected limb parameters reveal significant improvement in the favor of study group. While the results of step length of the affected limb parameters reveal no significant difference between study and control groups.

\section{DISCUSSION}

The goal of our study was to improve walking speed of children with hemiparetic cerebral palsy through using of closed kinematic chain exercise of the pedaling machine. Slow walking speed for children with cerebral palsy represents a major problem that restricts their ability to interact functionally in the community and with their peers [13]. Closed kinematic chain exercises help converting strength improvement into enhancement in functional motor performance [14]. Pedaling was used to improve walking speed of children by promoting motor relearning, muscle strengthening, improving endurance and helping the child to practice smooth alternative movement then a better motor performance during ambulation will be assisted. Pedaling is an appropriate cerebral palsy exercise that improve oxygen uptake, physical endurance and strength [15].

The child with cerebral palsy has a problem to contract his muscle in an isolated movement as a result of poor selective motor control and inability to coactivate the antagonistic muscle during either free movements or phasic movements which leads to imbalanced and uncoordinated ambulation [16]. Pedaling helps to improve strength of the lower limb muscles without the need to load the muscles in an isolated joint range as the muscles work together in harmony in an alternative pattern of flexion and extension out of the pathological pattern. Pedaling helps children to move their legs in a speed that is not possible during ordinary daily living activities which have a positive influence on muscle physiology and neuromotor control [17].

In this study speed of walking was increased significantly $(p<0.05)$ in the study and control groups the improvement percent in the study group was $35.49 \%$ while in the control group was $1.17 \%$. This improvement in the study group might be as a result of pedaling training as in contrast to walking or running, pedaling causes less joint pain and muscle spasm, needs less coordination and balance and provides a passive guidance to more symmetrical wide range alternative joint movement [18].

Improvement in the speed parameter in the study group might be as a result of the improvement of step length of the affected and non-affected limbs of the study group children.

Previous studies have found that pedaling improved physical endurance as a result of improving oxygen consumption, gross motor function and oxygen uptake but none of these studies recorded an improvement in walking speed. A previous study applied on 70 ambulatory children with spina bifida reported an improvement in walking speed and step length after 4 weeks of repetitive ergometer training $[18,19]$. 
It had been noticed that children in the study group encountered some difficulties to perform smooth regular Pedaling pattern at the first few sessions but their abilities were improved with continuous encouragement, motivation and enhancing the children to use visual feedback to try to cycle more regularly. Instead of that pedaling is a safe and effective mode of exercise that cause improvement in ambulation without enhancing the abnormal muscle activity, children with cerebral palsy finds some difficulties in regular cycling as a result of co-contraction of muscles and exhibits a muscle activity of a longer period than typically developed children [20]. In a study of stroke patient examined kinetics and kinematics of cycling it was found that visual feedback enhanced muscle power, neuromuscular control, cycling smoothness and overall cycling performance which helped to learn more symmetrical activation of muscles [21].

\section{CONCLUSION}

Pedal exercise training helps in improvement of average speed and step length of walking in children with hemiparetic cerebral palsy.

\section{Conflicts of interest: None}

\section{REFERENCES}

[1]. Mancini MC, Fiúza PM, Rebelo JM, Magalhães LC, Coelho ZAC, Paixão ML, et al. Comparison of functional activity performance in normally developing children and children with cerebral palsy. Arq Neuropsiquiatr. 2002;60(2):446-52.

[2]. Gage JR. Gait analysis in cerebral palsy. In: Clinics in developmental medicine. Mac Keith Press; 1991.

[3]. Seifart A, Unger M, Burger M. The effect of lower limb functional electrical stimulation on gait of children with cerebral palsy. Pediatr Phys Ther [Internet]. 2009;21(1):23-30. Available from: http:// www.ncbi.nlm.nih.gov/pubmed/19214073

[4]. Brown DA, Kautz SA. Pedaling Exercise in Persons With Poststroke Hemiplegia. Stroke. 1998;29(153):598-607.

[5]. Hutton JL. Effect of severity of disability on survival in north east England cerebral palsy cohort. Arch Dis Child [Internet]. 2000;83(6):468-74. Available from: http://adc.bmj.com/content/83/6/468.abstract

[6]. Rowe PJ, Durward B, Baer G. Functional human movement: measurement and analysis. ButterworthHeinemann; 1999.

[7]. BenAbdelkader C, Cutler R, Davis L. Stride and cadence as a biometric in automatic person identification and verification. Proc - 5th IEEE Int Conf Autom Face Gesture Recognition, FGR 2002. 2002;372-7.

[8]. Gage JR, Deluca PA, Renshaw TS. Gait Analysis: Principles and Applications. Am Acad Orthop Surg. 1995;77(10):1607-23.
[9]. Gharib NM, El-Maksoud GM a., Rezk-Allah SS. Efficacy of gait trainer as an adjunct to traditional physical therapy on walking performance in hemiparetic cerebral palsied children: a randomized controlled trial. Clin Rehabil. 2011;25(10):924-34.

[10]. Burnfield JM, Shu Y, Buster T, Taylor A. Perry Issue/ : Training and Walking/: Implications for Practice. 2010;90(2):289-305.

[11]. Rimmer JH. Physical fitness levels of persons with cerebral palsy. Dev Med Child Neurol. 2001;43(3):20812.

[12]. Palisano R, Rosenbaum P, Walter S, Russell D, Wood E, Galuppi B. Development and reliability of a system to classify gross motor function in children with cerebral palsy. Dev Med Child Neurol. 1997;39(2):21423.

[13]. Pirpiris M, Wilkinson A, Rodda J, Nguyen T, Baker R, Nattrass $G$, et al. Walking speed in children and young adults with neuromuscular disease: comparison between two assessment methods. J Pediatr Orthop [Internet]. 2003;23(3):302-7. Available from: http://journals.Iww.com/pedorthopaedics/Abstract/ 2003/05000/Walking_Speed_in_Children_ and_Young_Adults_With.6.aspx

[14]. Blundell SW, Shepherd RB, Dean CM, Adams RD, Cahill BM. Functional strength training in cerebral palsy: a pilot study of a group circuit training class for children aged 4-8 years. Clin Rehabil. 2003;17(1):48-57.

[15]. Shinohara T, Suzuki N, Oba M, Kawasumi M, Kimizuka $M$, Mita K. Effect of exercise at the AT point for children with cerebral palsy. Bull Hosp Jt Dis [Internet]. 2003;61(1-2):63-7. Available from: http:// www.ncbi.nlm.nih.gov/pubmed/12828382

[16]. Bryanton C, Bossé J, Brien M, McLean J, McCormick a, Sveistrup $H$. Feasibility, motivation, and selective motor control: virtual reality compared to conventional home exercise in children with cerebral palsy. Cyberpsychol Behav. 2006;9(2):123-8.

[17]. Fowler EG, Knutson LM, Demuth SK, Siebert KL, Simms VD, Sugi $M H$, et al. Strengthening ( PEDALS ) for Children Stationary Cycling/: A Randomized. Phys Ther. 2010;90(3).

[18]. Sharma S. Methodology for Study of the Effect of Cyclic Ergo Meter Exercise on Improving Gait Parameters in Ambulatory Spina Bifida Children. Int J Educ Plan Adm. 2011;1(2):109-17.

[19]. Williams $H$, Pountney T. Effects of a static bicycling programme on the functional ability of young people with cerebral palsy who are non-ambulant. Dev Med Child Neurol. 2007;49(7):522-7.

[20]. Kaplan SL. Cycling patterns in children with and without cerebral palsy. Dev Med Child Neurol. 1995;37(7):620-30.

[21]. Lin SI, Lo CC, Lin PY, Chen JJJ. Biomechanical assessments of the effect of visual feedback on cycling for patients with stroke. J Electromyogr Kinesiol [Internet]. 2012;22(4):582-8. Available from: http:// dx.doi.org/10.1016/j.jelekin.2012.03.009

How to cite this article: Nahla M. Ibrahim, Mai Elsayed Abbass. EFFECT OF PEDAL TRAINING ON GAIT SPEED IN CHILDREN WITH HEMIPARETIC CEREBRAL PALSY. Int J Physiother Res 2017;5(6):2560-2565. DOI: 10.16965/ ijpr.2017.249 